\title{
Drug repurposing patent documents vs peer review: patent information comes more than 600 days earlier on average
}

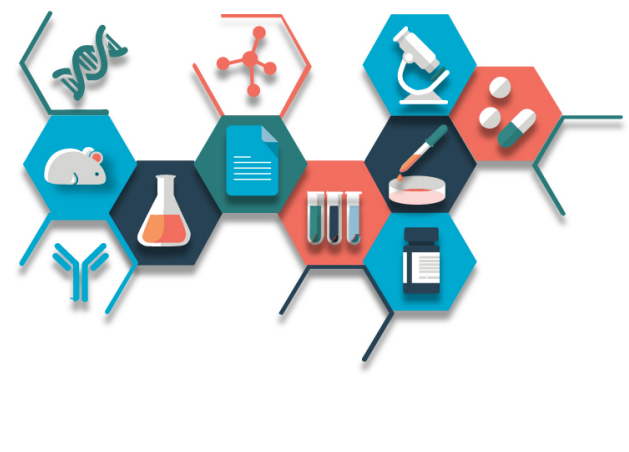

\author{
Hermann Mucke ${ }^{*, 1}$ (iD) \& Peter Mucke ${ }^{1}$ \\ ${ }^{1}$ H.M. Pharma Consultancy, Enenkelstr, 28/32, Vienna, A 1160, Austria \\ *Author for correspondence: h.mucke@hmpharmacon.com
}

\begin{abstract}
"our data show that the fraction of patent applications that get a peer-reviewed companion paper published only after the public disclosure of the invention (or not at all, at least not within 2-5 years) is between 67 and 75\%."
\end{abstract}

First draft submitted: 8 January 2020; Accepted for publication: 21 January 2020; Published online: 19 March 2020

Keywords: drug repositioning • drug repurposing • intellectual property $\bullet$ scientific publishing

Drug developers require access to scientific information in as close to real time as possible. The commonly employed formal sources are peer-reviewed journals and conference presentations. Another extremely important information source, the intellectual property documents, is widely ignored.

For many years, we have been screening the international patent applications of the World Intellectual Property Office (WIPO, Geneva, Switzerland) - which are the formal disclosures made under the Patent Convention Treaty (PCT) - for several thematic categories including inter alia and drug repurposing. It soon became apparent that this subset of intellectual property documents offers a particularly pronounced information advantage over the subject matter represented in peer-reviewed journals. As this is almost totally uncharted territory [1], we decided to investigate how many of these documents have peer-reviewed companion papers and when they are published in relation to the corresponding patent document.

The WIPO's online database, PatentScope [2], was used as the sole source of patent information. It offers no option to search for documents that deal with known active pharmaceutical ingredients in unapproved or previously unknown therapeutic applications. Therefore, we examined all document titles and abstracts published under IPC Code A61K (which covers drugs) for known substance classes, drugs, drug candidates or other compounds for which the wording was suggestive of drug repurposing; in other words, for use in a new therapeutic indication that is not simply a use extension, such as from one type of cancer to another. These documents were flagged and in a second round of investigation body text and claim sections were examined to confirm or reject drug repurposing status.

The third step consisted of a PubMed search to identify a peer-reviewed companion paper - defined as having at least one patent inventor as an author and a substantial part of the patent application as a subject - for each drug repurposing patent document. An author search was carried out for all inventor names in each patent document as a first tier and each hit was examined for contextual congruence with the respective patent, in a time window starting 3 years prior to the publication date of the intellectual property document up to the present. If no congruence was found, pivotal keywords (compound nonproprietary names, drug targets, mechanisms or pathways) were extracted from the patent document and combined with the institutional applicant. If this returned a clearly congruent peer-reviewed hit within the same time frame, the hit was also considered a companion paper. The earliest public availability date (the 'Epub' online date, or the print date if no Epub date was available) and the digital object identifier were recorded and linked to the respective patent document.

We found that the number of PCT drug repurposing patent applications has risen consistently between 2015 and 2019 and did so more strongly than the total number of A61K publications, raising their share from $0.69 \%$ in 
Table 1. Numbers and shares of Patent Convention Treaty drug repurposing patent applications that had their peer-reviewed companion (if any) published before or after the patent document, 2015-2017.

\begin{tabular}{|llll|}
\hline Year & Patent earlier than peer review & Patent later than peer review & No peer review companion \\
2017 & $31(27.4 \%)$ & $25(22.1 \%)$ & $57(50.4 \%)$ \\
\hline 2016 & $23(25.0 \%)$ & $20(21.7 \%)$ & $49(53.3 \%)$ \\
\hline 2015 & $27(32.9 \%)$ & $18(22.0 \%)$ & $37(45.1 \%)$ \\
\hline
\end{tabular}

2015 to $0.91 \%$ in 2019, while increasing their numbers from 82 in 2015 to 142 in 2019 . A total of 550 intellectual property documents related to drug repurposing were identified during this 5-year interval.

An interesting finding emerged when we started to correlate and analyze publication dates for patent/peerreviewed document pairs from the 2015 to 2017 period. From our current general experience in the pharmaceutical sciences and from an analysis in the vascular risk management sector that we had published several years ago [3], we had assumed that peer-reviewed documents would become public quicker (if they existed at all) than the corresponding patent documents. In contrast, our data show that the fraction of patent applications that get a peer-reviewed companion paper published only after the public disclosure of the invention (or not at all, at least not within 2-5 years) is between 67 and 75\% (Table 1). Looking at patent disclosures published in 2015, those that were ahead of their peer review companion papers (if any) had an average time advantage of 629 days. Those that lagged behind their companions did so by 400 days. In total, PCT documents published in 2015 that had a peer review companion paper were 218 days ahead of it on average. Because even some patent documents published in 2015 had peer-review companions with Epub dates in the last quarter of 2019, we did not extend this analysis to documents published in 2018 and 2019. The fact that the share of patent documents without peer-reviewed companions consistently continued the rise evidenced in Table 1 during these most recent years (data not shown) suggests that many patent documents from this interval may still get their peer review counterparts published.

Finally, in Table 2 we disclose the patent application/peer-review document pairs for 2015, the latest year for which the great majority of peer-reviewed papers can be assumed to have been published.

Life scientists, including those working in drug development, tend to ignore patents as a regular information source. While the reasons for this negligence are numerous, one often-heard statement - that any worthwhile information from patents can be found in the peer-reviewed literature - requires qualification. This is especially true in the field of drug repurposing which has experienced an impressive rise in peer-reviewed publications during recent years. In each of the 3 years that we analyzed in this respect (2015-2017) the patent document was more likely to reach the public earlier, in some cases years earlier, if it existed at all - which was not the case for about half of all patent documents published during this period.

Our data from 2015 to 2019 also show that interest in international patenting drug repurposing findings seems to rise quicker than peer-reviewed publication rates. One conceivable explanation for both phenomena might be that drug repurposing work can lead to relatively quick results, requiring prompt patent filings which then trigger a tightly paced disclosure process. In any case, scientists and analysts working in this field would do well to include international PCT patent disclosures in their monitoring.

Our analysis, which we believe to be the first of this type to be published, has an obvious limitation: patent documents were identified by manual screening of PatentScope titles and abstracts. Documents which revealed drug repurposing only in their body text or claims section could have been missed. From our unrelated work with pharmaceutical patents we believe that this miss rate is less than $10 \%$ and in any case is not likely to have changed the outcome of our analysis.

The type of search employed by us is suited to machine learning, which could include the entire patent texts [4] while searching for alternate compound designations and chemical structures [5] which in our work could rely only on the searcher's experience. The system could then be expanded toward the companion peer review paper searches and proper pairings. Our dataset could serve as a comparator and means of calibration for such systems. 
Table 2. The drug repurposing Patent Convention Treaty patent application/peer-reviewed document pairs of patents published in 2015 and their temporal offset.

\begin{tabular}{|c|c|c|c|}
\hline PCT publication number & Peer review DOI & $\begin{array}{l}\text { Offset of PCT vs peer } \\
\text { review (days) }{ }^{\dagger}\end{array}$ & Subject matter \\
\hline WO/2015/189597 & 10.3892/ijo.2016.3567 & -173 & Low-dose naltrexone for priming of cancer cells for therapy \\
\hline WO/2015/187847 & 10.1016/j.stem.2017.08.001 & -629 & $\begin{array}{l}\text { Prostaglandin E1 and misoprostol for chronic myelogenous/myeloid } \\
\text { leukemia }\end{array}$ \\
\hline WO/2015/184260 & $10.1101 /$ gr.190629.115 & +49 & Anticonvulsants for epigenetic mendelian disorders \\
\hline WO/2015/181412 & 10.1371/journal.pone.0111184 & +408 & Theobromine for urolithiasis \\
\hline WO/2015/173788 & 10.1016/j.antiviral.2017.03.024 & -500 & $\begin{array}{l}\text { Anti-infective strategy against influenza and Staphylococcus } \\
\text { aureus infection }\end{array}$ \\
\hline WO/2015/170248 & $10.1186 / 1479-5876-12-128$ & +540 & Nelfinavir, metformin and rosuvastatin for cancer \\
\hline WO/2015/166277 & 10.1172/jci.insight.87001 & -273 & Aldehyde dehydrogenase inhibitors for fibrosis \\
\hline WO/2015/165856 & $10.1111 /$ bjd. 16930 & -1047 & Artemisinin for seborrheic keratoses \\
\hline WO/2015/157223 & 10.1371/journal.pone.0194868 & -889 & Various compounds for coronavirus infection \\
\hline WO/2015/154820 & 10.1016/j.antiviral.2013.10.003 & +725 & Anti-inflammatory agents for viral infections \\
\hline $\begin{array}{l}\text { WO/2015/149706 } \\
\text { WO/2015/149707 }\end{array}$ & $10.1073 /$ pnas. 1416166111 & +304 & Fingolimod for ischemic stroke \\
\hline WO/2015/147411 & $10.1038 /$ cddis.2014.266 & +462 & Mitochondrial complex I inhibitors for proliferative vitroretinopathy \\
\hline WO/2015/143367 & 10.1016/j.cct.2016.02.012 & -160 & Cenicriviroc for fibrosis \\
\hline WO/2015/127163 & 10.3324/haematol.2019.226720 & -1526 & Pyridoxamine for sickle cell disease and thalassemia \\
\hline WO/2015/120254 & $10.1093 /$ carcin/bgt366 & +646 & Disulfiram for brain tumors \\
\hline WO/2015/120206 & 10.18632/oncotarget.7283 & -222 & MAO inhibitors for brain cancers \\
\hline WO/2015/110949 & 10.1038/leu.2016.5 & -188 & Imatinib for hypercholesterolemia \\
\hline WO/2015/110593 & 10.1093/ofid/ofv155 & -147 & Endothelin receptor B antagonists for cytomegalovirus infection \\
\hline WO/2015/108985 & $10.4088 / J C P .13 c r 08917$ & +342 & Ketamine for autism spectrum disorders \\
\hline WO/2015/106678 & $10.24272 / \mathrm{j}$. issn.2095-8137.2020.012 & -1607 & Progesterone for altitude sickness \\
\hline WO/2015/095757 & 10.1073/pnas. 1523005113 & -298 & Roxadustat for retinopathy of prematurity \\
\hline WO/2015/091857 & $10.1038 / \mathrm{nm} .3827$ & +101 & Modulators of intracellular chloride for Down syndrome \\
\hline WO/2015/079413 & 10.1126/scisignal.2005537 & +135 & Synaptojanin-2 inhibitors for cancer \\
\hline WO/2015/079031 & 10.1016/j.tracli.2013.03.005 & +750 & XPO1 inhibitors for beta-thalassemia \\
\hline WO/2015/076430 & $10.1155 / 2014 / 973986$ & +281 & Metformin for immune diseases \\
\hline WO/2015/073804 & $10.1038 /$ srep 03743 & +489 & Various compounds for malaria \\
\hline WO/2015/073697 & $10.1186 / \mathrm{s} 12974-018-1208-3$ & -1120 & Laquinimod for glaucoma \\
\hline WO/2015/065136 & $10.1167 /$ iovs. $15-18065$ & -313 & Masitinib for vascular permeability disorders \\
\hline WO/2015/065135 & $10.1007 / \mathrm{s} 12272-016-0872-z$ & -590 & Dasatinib for vascular permeability disorders \\
\hline WO/2015/060702 & 10.1016/j.pbb.2017.07.009 & -814 & S-phenotropil for obesity \\
\hline WO/2015/059114 & $10.1097 /$ CEJ.0000000000000333 & -1172 & Yellow fever vaccine for breast cancer prevention \\
\hline WO/2015/053452 & 10.1371/journal.pone.0094978 & +374 & Silmitasertib as a splicing regulator \\
\hline WO/2015/049608 & 10.1016/j.eplepsyres.2017.08.006 & -863 & Propylparabene for neuroprotection in status epilepticus \\
\hline WO/2015/046857 & $10.1089 /$ thy. 2017.0338 & -1091 & Metformin for autoimmune thyroid diseases \\
\hline WO/2015/044762 & 10.1016/j.ejmech.2017.05.034 & -771 & Cefazolin as an inhibitor of IL-15 and IL-2 receptors \\
\hline WO/2015/026939 & 10.1016/j.bcmd.2015.10.004 & -243 & Chemical inducers of fetal hemoglobin expression for sickle cell disease \\
\hline WO/2015/026849 & $10.1038 /$ ncomms3410 & +541 & Clemizole for epilepsy \\
\hline WO/2015/023871 & 10.1111/adb.12106 & +465 & Ibudilast for alcoholism \\
\hline WO/2015/013591 & $10.1007 / \mathrm{s} 10620-014-3157-8$ & +273 & Rifaximin for irritable bowel syndrome \\
\hline WO/2015/011246 & $10.5665 /$ sleep. 5854 & -489 & Flecainide as a modafinil potentiator \\
\hline WO/2015/007869 & $10.1016 / j$. redox.2018.05.014 & -1225 & Local anesthetics for cancer \\
\hline WO/2015/006319 & None (PMID: 24595578) & +306 & Ivermectin for papulopustular rosacea \\
\hline WO/2015/006305 & $10.1111 /$ bjd. 13408 & -27 & Ivermectin for rosacea \\
\hline WO/2015/004470 & 10.1016/j.hrthm.2015.05.027 & -132 & Hydroxychloroquine for cardiovascular diseases \\
\hline WO/2015/001799 & 10.1128/AAC.01614-15 & -470 & Clofazimine for babesiosis \\
\hline
\end{tabular}




\section{Financial \& competing interests disclosure}

The authors have no relevant affiliations or financial involvement with any organization or entity with a financial interest in or financial conflict with the subject matter or materials discussed in the manuscript. This includes employment, consultancies, honoraria, stock ownership or options, expert testimony, grants or patents received or pending, or royalties.

No writing assistance was utilized in the production of this manuscript.

Open access

This work is licensed under the Attribution-NonCommercial-NoDerivatives 4.0 Unported License. To view a copy of this license, visit http://creativecommons.org/licenses/by-nc-nd/4.0/

\section{References}

1. Mucke HAM. Drug repositioning in the mirror of patenting: surveying and mining uncharted territory. Front. Pharmacol. 8, 927 (2017).

2. PatentScope. World Intellectual Property Organization (2019). https://patentscope.wipo.int/search/en/search.jsf

3. Mucke H. Relating patenting and peer-review publications: an extended perspective on the vascular health and risk management literature. Vasc. Health Risk Manag. 7, 265-272 (2011).

4. Bergeaud A, Potiron Y, Raimbault J. Classifying patents based on their semantic content. PLoS ONE 12(4), e0176310 (2017).

5. Akhondi SA, Rey H, Schwörer M et al. Automatic identification of relevant chemical compounds from patents. Database 2019, baz001 (2019). 